\title{
La espiritualidad en san Pablo
}

\section{INTRODUCCIÓN}

Quiero que mis primeras palabras sean para dar gracias al Señor por haberme llamado a la fe, que educaron mis padres, catequistas y profesores; por haberme regalado el don del Episcopado sin mérito alguno de mi parte, y haberme confiado la amada Diócesis de Coria-Cáceres para apacentarla en comunión con el Sucesor de Pedro, el Santo Padre Benedicto XVI, y con todos los Obispos de la Iglesia.

Agradezco también al Rvd. Padre, director del Estudio Agustiniano, su gesto fraterno de invitarme a ofrecer la lección inaugural del Curso 20082009. Precisamente en esta Institución, hace pocos años, ofrecía las lecciones de Espiritualidad. Aquí vuelvo con humildad y profundo gozo, a encontrarme con los hermanos de antes, de ahora y de siempre.

Vengo a esta hermosa y entrañable ciudad de Valladolid, orgullo de esta Comunidad de Castilla-León y de España a la que he intentado servir desde el Señor y el Evangelio durante tantos años. Sabed que mi corazón está lleno de vuestros rostros, de vuestras historias, de vuestra fe... y que sois peregrinos en mi alma...

Y vengo a ofreceros la "Lección Inaugural" del presente Curso Académico 2008-2009, que tiene como título: "La espiritualidad en San Pablo". Un tema siempre atrayente y siempre nuevo. Un tema que debe ocupar nuestra atención permanente. Un tema muy amplio del que intentaré ofrecer una síntesis.

Juan Pablo II nos advirtió de la necesidad de atender la espiritualidad ya que se preguntaba: “¿No es acaso un "signo de los tiempos" el que hoy, a pesar de los vastos procesos de secularización, se detecta una difusa exigencia de espiritualidad, que en gran parte se manifiesta precisamente en una renovada necesidad de orar?" (NMI 33).

K. Rahner dijo que "el cristiano del siglo XXI será un místico o no será"; se subentiende "no será cristiano". Este teólogo nos dice que en un mundo cada día más secularizado, en el que lo religioso va desapareciendo, sólo aquel 
cristiano que esté fuertemente arraigado en el misterio de Dios podrá resistir la presión social de los sectores increyentes, ateos, agnósticos, indiferentes... La experiencia espiritual es necesaria para acceder o perseverar en la fe.

Desarrollaré este tema, con la ayuda del Señor y contando con vuestra reconocida benevolencia y siempre agradecida amistad.

\section{I \\ ¿EN QUÉ CONSISTE LA ESPIRITUALIDAD?}

La espiritualidad cristiana, que se diferencia de la espiritualidad simplemente humana, es una realidad compleja y rica de contenido. De forma sintética y abreviada, exponemos su naturaleza.

* La espiritualidad cristiana comporta una relación esencial al Espíritu Santo y a su acción. Por eso, la espiritualidad es la vida en el Espíritu Santo y según el Espíritu Santo que se hace presente en la Iglesia; es la vida suscitada, comunicada por el Espíritu Santo; es la vida impulsada por el Soplo y el Aliento de este mismo Espíritu. Bien lo dijo San Pablo: "Los que se dejan guiar por el Espíritu de Dios, esos son sus hijos" (Rm. 5, 18); "Caminamos según el Espíritu" (Rm. 8,4). La esencia de la espiritualidad cristiana consiste en que el cristiano por el sacramento del Bautismo recibe el don de la vida divina que lo renueva intrínsecamente y lo transforma ontológicamente en una "criatura nueva", insertando en él un nuevo principio de vida que se manifiesta en un modo peculiar y específico de ser y de actuar, el propio de Jesucristo nuestro Señor (cf. Rm. 8, 15). Por eso, decimos que la espiritualidad cristiana consiste en vivir la existencia humana en todas sus dimensiones dejándose guiar y conducir, renovar y transformar, mover y actuar, por el Espíritu Santo en todo como Jesús de Nazaret. De esta manera, cada cristiano se santifica en su propio estado de vida y circunstancia por un proceso de configuración y sintonía con Cristo, en el Espíritu Santo, según los designios del Padre (cf. Ef. 5,2). Teniendo en cuenta lo escrito, podemos afirmar que persona espiritual es aquella que está abierta al Espíritu Santo, se deja iluminar y guiar por este mismo Espíritu que inquieta, renueva, purifica, alerta, envía, asiste, acompaña, hermana... Juan Pablo II, en conformidad con estas palabras del Apóstol afirma: "la existencia cristiana es "vida espiritual", o sea, vida animada y dirigida por el Espíritu hacia la santidad o perfección de la caridad" (PDV 19,3). 
* La espiritualidad cristiana no queda confinada en la interioridad del hombre, sino que ha de dar frutos de caridad para la vida del mundo" (OT 16). Más aún, la vida espiritual dice también relación al mundo (AA 32). Guiados por el Espíritu Santo y bajo las enseñanzas de la Iglesia, el hombre espiritual ha de abrirse al mundo para renovarlo, transformarlo y hacerlo más conforme a los designios de Dios. Por ello, hemos de promover e intensificar una espiritualidad de la acción y del compromiso.

* Hay una espiritualidad cristiana común para todos y cuyos rasgos más peculiares son los siguientes:

- Una experiencia del Dios de Jesucristo: de Dios Padre, Hijo y Espíritu Santo.

- La confesión y seguimiento de Jesucristo, identificándonos con sus actitudes, con su espíritu, con sus valores, que Jesús encarnó, y que ahora nosotros debemos vivir ahora como discípulos suyos

- Una vida de amor fraterno y de compromiso real con los hermanos, especialmente con los pobres y desvalidos, que sea signo de la praxis de Jesús de Nazaret.

- Participación en los sacramentos de la Iglesia a través de los cuales recibimos la salvación que nos da el Padre por Cristo en el Espíritu.

- Celebración comunitaria de la fe, del amor y de la esperanza en el seno de la Iglesia de Jesucristo, fortaleciendo continuamente la comunión.

- Una esperanza que trasciende la muerte y espera la salvación definitiva más allá de la historia, pero que intenta hacer presente en este mundo el Reino de la verdad y la vida, del amor y de la paz, de la gracia y de la santidad, de la libertad y de la justicia.

Sobre este tronco único se fundamentan otras espiritualidades específicas, peculiares y distintas entre sí: la espiritualidad de los Laicos, la de los Religiosos y Religiosas, y la los Sacerdotes.

\section{II}

\section{DIMENSIONES DE LA ESPIRITUALIDAD}

Una vez que hemos presentado la semblanza de la espiritualidad cristiana, pasamos a determinar y explicar cada una de sus dimensiones fundamentales. 


\section{DIMENSION TRINITARIA}

\section{EI misterio insondable de Dios}

La teología y la espiritualidad tienen una estructura constituida por su referencia al misterio insondable e inefable de Dios único en la Trinidad de personas, Padre, Hijo y Espíritu Santo. Misterio que nos desborda y nos sobrecoge. Como Moisés se acercó a la zarza que ardía sin consumirse con los pies descalzos, así nosotros hoy, con profundo respeto y en actitud adorante nos acercamos al misterio inefable e insondable de Dios.

Recordemos maravillados las palabras del Evangelio de Juan: "En el principio existía la Palabra, y la Palabra estaba junto a Dios y la Palabra era Dios" (Jn.1,1). Traigamos también a nuestros labios las palabras de la Carta a los Hebreos: "Este Hijo es resplandor de su gloria e impronta de su esencia" (Heb.1, 3). Realmente Dios es "el Padre de nuestro Señor Jesucristo" (IICor. 1,3). Vamos descubriendo que Dios no es soledad infinita; sino que es misterio de comunión personal. Pablo nos dice: "Gracia y paz a vosotros, de parte de Dios nuestro Padre y del Señor Jesucristo" (Rm. 1, 17; ITes. 1, 1). En el misterio insondable de Dios está también el Espíritu Santo: el abrazo sustancial de amor del Padre y del Hijo. La fórmula bimembre es completada y ampliada en otra trimembre. Así nos dice san Pablo: "la gracia de nuestro Señor Jesucristo, el amor de Dios y la comunión del Espíritu Santo sea con vosotros" (IICor. 13, 13; Rm. 15, 30; ICor. 12, 4ss; Gál. 4, 6; 2Tes. 2,13). Estas fórmulas constituyen la base para la posterior dogmática trinitaria de la Iglesia. Ahora podemos proclamar que Dios es misterio de comunión trinitaria, y no soledad eterna.

\section{La comunicación de Dios a la humanidad}

2.1. La primera misión: del Misterio Trinitario al Misterio de la Encarnación del Verbo del Padre.

Por puro amor y gracia el Padre envía a su Hijo al mundo para salvar y redimir al hombre, para realizar su designio de salvación: "Tanto amó Dios al mundo que dio a su Hijo único" (Jn. 3, 16). Este envío se realiza y se muestra en el misterio de la Encarnación del Verbo de Dios: "Y el Verbo se hizo carne y habitó entre nosotros" (Jn. 1, 14). San Pablo lo dice así: "Cuando llegó la plenitud de los tiempos, Dios envió a su Hijo, nacido de 
una mujer...para rescatar a los que estaban sujetos a la Ley, a fin de conferirnos la adopción filial" (Gál. 4,45). ). La misión visible del Hijo es única y constituye el centro de toda la historia de la humanidad y de la Nueva Alianza perfecta y definitiva. Jesucristo es el Emmanuel, el Dios-con-nosotros (Is. 7, 14). Jesús es el Dios-con-nosotros; el Dios injertado en las entrañas de la humanidad y de la historia, entroncado con los pobres y desvalidos, expulsado del mundo y crucificado por la ceguera y dureza de los hombres. Dios en Jesús se abaja tanto que asume la realidad humana para sanarla y transformarla, curarla y redimirla.

Cristo es la revelación plena del Padre (Jn. 1,18). Por eso dice San Juan de la Cruz: "Si yo te he dicho todo en mi Palabra que es mi Hijo, yo no tengo otra palabra que pueda ahora responder o revelar: míralo solamente porque yo te dicho y revelado todo en Él, y tú encontrarás más de lo que pides y deseas en Él" (Subida al Monte Carmelo", lib. II, cap. XXII, 5). Pablo nos invita a todos nosotros a alabar y dar gracias a Dios "Así todos juntos y a una sola voz alabaréis a Dios, Padre de nuestro Señor Jesucristo" (Rm. 15, 6). "El Dios y Padre del Señor Jesús, ¡bendito sea para siempre!" (II Cor. 11,31).

2.2.- La segunda misión. El Padre y el Hijo envían al Espíritu Santo a la humanidad. El Espíritu Santo nos ha sido dado.

"Dios ha enviado a nuestros corazones el Espíritu de su Hijo" (Gál. 4, 6); "el amor de Dios ha sido derramado en nuestros corazones por el Espíritu Santo que nos ha sido dado" (Rm. 5, 5); "El que nos marcó con su sello y nos dio en arras el Espíritu en nuestros corazones" (IICor. 1,22); "El que nos otorga el Espíritu" (Gál. 3, 5). Es, pues, Dios quien nos da el Espíritu Santo (ITes. 4,8; IICor. 1, 22), obra en nosotros por medio de Él (ICor. 2,10; IICor. 3,6). Por eso, nosotros no podemos ni merecer ni exigir el Espíritu Santo, sino sólo recibirlo y acogerlo con las manos vacías y abiertas, como un niño (cf. Rm. 8, 15). De este modo, podemos "estar llenos" del Espíritu Santo (Ef. 5, 18). ¡Dejémonos abrazar por el Padre por medio de sus brazos misteriosos y llenos de amor, ternura y misericordia que son su Eterno Hijo y el Espíritu Santo que de ambos procede desde toda la eternidad! De este modo seremos incorporados por gracia al Misterio de la Comunión Trinitaria. Asumamos con gozo y alegría la llamada a vivir en la Comunión Trinitaria para expresarla en las celebraciones sacramentales, en el trabajo evangelizador corresponsable y fraterno que nos lleve a ser signos de comunión y testigos de la misma en las relaciones con todos. Todo nos viene del Padre por Jesucristo en el Espíritu y todo retorna al Padre por Jesucristo en el Espíritu. 


\section{DIMENSIÓN CRISTOCÉNTRICA}

Dios se revela y se manifiesta como el Dios de la gracia y del perdón en y por medio de Jesucristo. Es mi intención desentrañar y explicar el enunciado que acabo de fijar ofreciendo la experiencia religiosa de San Pablo, en este Año dedicado a él. "El encuentro con Cristo en el camino de Damasco revolucionó literalmente su vida. Cristo se convirtió en su razón de ser y en el motivo profundo de todo su trabajo apostólico" (Benedicto XVI: Audiencia General, 15-XI-2006).

\section{La experiencia religiosa de san Pablo}

1.- "Mas la prueba de que Dios nos ama es que Cristo, siendo nosotros todavía pecadores, murió por nosotros" (Rm. 5,8$)$.

El amor de Dios va dirigido no tanto al justo, piadoso, santo, sino al pecador, al rebelde, al que lo niega, al que lo rechaza. El amor de Dios busca al hombre... G. Bornkamm: "El amor de Dios se ha hecho acontecimiento en la muerte de Cristo. Este amor no encuentra a su llegada nada que sea digno de él, sino sólo la debilidad, hombres sin Dios, pecadores y enemigos (cf. Rm. 5, 6-8). Su paradoja -que para la inteligencia humana es un absurdo- muestra su talla divina" ("Pablo de Tarso", Salamanca, 193).

2.- "Por gracia de Dios soy lo que soy" (ICor. 15, 10).

Pablo nos muestra el corazón y el punto central de su vida y de su fe. Nada de lo que él era lo atribuía a su mérito, a sus obras. Todo era don y gracia de Dios y de su amor. Dios era la única potencia de su existencia. No podemos salvarnos con nuestras propias buenas obras ya que la salvación es don de Dios que acogemos en la fe. Con la gracia de Dios es siempre posible un nuevo inicio. Con la ayuda del Señor podemos decir sí a Dios, podemos hacer realidad el "inicio de la fe"...

3.- "Pablo, siervo de Cristo Jesús, llamado al apostolado, elegido para predicar el evangelio de Dios acerca de su Hijo, nacido de la descendencia de David..." (Rm. 1, 1-3). "Pablo, Apóstol no por autoridad humana ni gracias a un hombre, sino por Jesucristo y Dios Padre que le resucitó de entre los muertos" (Gál. 1, 1).

Las credenciales de Pablo no son títulos académicos ni nombramientos humanos, sino la elección y llamada gratuitas de Cristo y el encargo y misión 
que le ha confiado de "llevar su Santo Nombre a todos los pueblos de la tierra". Pablo es vaso de elección para llevar el evangelio de la salvación a todas las naciones. Pablo es servidor de Cristo y servidor de los hombres.

4.- "Vivo en la fe del Hijo de Dios que me amó y se entregó por mí" (Gál. 2, 20).

La fe de san Pablo no es otra cosa que la experiencia de ser amado personalmente por Jesucristo; más aún, es la toma de conciencia de que Jesucristo murió por amor a él, y, cómo resucitado, sigue amándolo. La fe de Pablo estriba en haber sido alcanzado por el amor gratuito y salvador de Jesucristo. Un amor que lo trastorna hasta lo más íntimo de sí mismo y lo transforma desde sus raíces más hondas. Su fe no es una mera opinión sobre Dios y del mundo. Su fe es el impacto que ha dejado el amor de Dios en su corazón. Por eso, podemos afirmar que esa misma fe es amor a Jesucristo.

5.- "Vivo yo, pero no soy yo, es Cristo quien vive en mí" (Gál. 2, 20).

¡Qué admirable progresión! Es necesario hacer esta gran "travesía": de "estar con el Señor" (Mc. 3,14), a "permanecer en el Señor" (Jn. 15, 5), a que "el Señor viva en mí" (Gál. 2, 20). Sí, nos hemos hecho una misma cosa con Él por el Bautismo que nos ha injertado en el misterio de su muerte y de su resurrección (cf. Rm. 6, 5).

6.- "Todo lo estimo pérdida, comparado con la excelencia del conocimiento de Cristo Jesús, mi Señor, por quien perdí todas las cosas, y las tengo por basura para ganar a Cristo, y ser hallado en él, no con la justicia mía, la que viene de la Ley, sino la que viene por la fe de Cristo, la justicia que viene de Dios, apoyada en la fe..." (Fil. 3, 8).

La experiencia vivida por Pablo en el encuentro con Jesucristo ha sido tan fuerte que le ha provocado un cambio profundo e inmenso: olvida todo su pasado y se proyecta decididamente hacia el futuro. Y es que para Pablo el Evangelio no era una doctrina sino una Persona: Jesucristo. El amor que Pablo profesa a Jesucristo es tan grande que le lleva a hacer y a vivir en adelante una opción muy peculiar en su propia vida: todo lo suyo por grande que fuera es efímero y nada vale ante Jesucristo. Por eso Pablo ya no vuelve sus ojos hacia atrás, sino que mira a Jesucristo y a Él se entrega con alma, corazón y vida.

7.- "Para mí la vida es Cristo, y la muerte, ganancia. $Y$ aunque vivir en la carne es para mí trabajo fructuoso, todavía no sé qué elegir. Por ambas partes me siento apretado, pues de un lado deseo morir para estar con Cristo, que es mucho mejor" (Fil. 1, 24-26).

El gran deseo de Pablo es "partir y estar con Cristo" (Fil. 1, 23). Por eso dirá: "Si vivimos, para el Señor vivimos y, si morimos, morimos para el Señor. Así que, ya vivamos ya muramos, del Señor somos" (Rm. 14,8). "Si morimos 
con Cristo, también viviremos con Él” (Rm. 6, 8). “...hasta hacerme semejante a Él en su muerte, tratando de llegar a la resurrección de entre los muertos" (Fil. 3, 10). "Conocer a Cristo, el poder de su resurrección y la comunión en sus padecimientos hasta hacerme semejante a él en su muerte, tratando de llegar a la resurrección de entre los muertos" (Fil. 3, 10).

8.- "Por la cruz de Cristo, el mundo es para mí un crucificado y yo un crucificado para el mundo" (Gál. 6, 14).

Pablo ha roto definitivamente con el mundo porque se ha unido para siempre con Jesucristo. Nosotros predicamos a un Cristo crucificado: escándalo para los judíos, necedad para los gentiles; mas para los llamados, lo mismo judíos que griegos, un Cristo, fuerza de Dios y sabiduría de Dios" (ICor. 1, 23-24).

9.- "Completo en mi carne lo que falta a la pasión de Cristo" (Col. 1, 24). "Entre los pretorianos y para todos los demás ha llegado a ser notorio que llevo mis cadenas en Cristo" (Fil. 1, 13).

San Pablo sufre por Jesucristo, no por razones políticas. Pablo desea para los demás lo que Jesús fue para él, es decir, el Señor que entrega su vida por los hermanos, para que se les restituya al pueblo la posesión de la justicia y de la libertad. Esta entrega es muy concreta: por amor a los hermanos y a las hermanas, Pablo se gloría de vivir del propio trabajo (IICor. 11, 7-11); se sacrifica a sí mismo y soporta luchas y persecuciones, viajes y cansancios, el peso de cada día (IICor. 11, 23-27); sufre con los que sufren (IICor. 11,29). Por eso llega a decir: "Yo, Pablo, el prisionero de Cristo Jesús por vosotros los gentiles" (Ef. 3,1). "Ahora me alegro de mis padecimientos por vosotros y suplo en mi carne lo que falta a las tribulaciones de Cristo por su cuerpo, que es la Iglesia" (Col. 1,20).

10.- "Que nos tengan los hombres por servidores de Cristo y administradores de los misterios de Dios. Ahora bien, lo que se exige de los administradores es que sean fieles" (ICor. 4, 1).

Pablo se autodefine como es: "servidor de Cristo y administrador de los misterios de Dios". Y esto es don y gracia de Dios, y lo vive en claves de agradecimiento y de fidelidad al Señor que lo ha enviado y a quien sirve.

11.- "Corro hacia la meta, con la vista en el premio al que Dios llama desde lo alto en Cristo Jesús" (Fil. 3, 14).

Pablo sabe que su caminar por la vida no le lleva a la nada ni al abismo, sino al Señor. Pablo sabe que el Señor lo acogerá en su muerte; no lo dejará tirado en la nada. Pablo se muestra esperanzado. En su relación con Jesucristo, lo verdaderamente importante y esencial no es la muerte sino el amor. Pablo está firmemente convencido de que es Dios quien lo ama y lo protege...". Si Dios está con nosotros, ¿quién estará contra nosotros?" (Rm. 
8,31). ¡Cuánto tenemos que aprender! Y, sobre todo, ¡cuánto nos queda por experimentar y vivir!

C

\section{DIMENSIÓN PNEUMATOLÓGICA}

El Espíritu Santo es el agente y el protagonista de la vida espiritual (PDV 27). Por ello, no podemos ni debemos silenciar al Espíritu Santo al hablar de la espiritualidad cristiana. Desentrañemos de forma abreviada la acción del Espíritu Santo en la espiritualidad.

\section{1.- El Espíritu Santo habita en los justos}

El Espíritu Santo "habita" (Rm. 8,9) en el cristiano como en su templo (cf. Rm. 8, 9). Pablo se dirige a los cristianos de Roma y les da una excelente y buena noticia: "Vosotros ya no estáis en la carne, sino en el espíritu, ya que el Espíritu de Dios habita en vosotros. El que no tiene el Espíritu de Cristo, no le pertenece" (Rm. 8,9). Estamos, pues, ante una realidad entrañable de nuestra fe cristiana: la presencia de Dios en el corazón de los creyentes. Es el misterio de la inhabitación de la Stma. Trinidad en el alma del justo. No estamos solos en la vida. En nosotros habita el Espíritu Santo y con Él el Padre y el Hijo. Somos así templos de la Stma. Trinidad; lugar donde habita y mora Dios.

\section{2.- El Espíritu Santo y las maravillas divinas en nosotros}

2.1.- El Espíritu Santo nos ha hecho renacer a la vida de Dios: "Mas cuando se manifestó la bondad de Dios nuestro Salvador y su amor a los hombres, él nos salvó no por obras de justicia que hubiésemos hecho nosotros, sino según su misericordia, por medio del baño de regeneración y de renovación del Espíritu Santo que él derramó con largueza por medio de Jesucristo..." (Tit. 3, 4-6). Esta transformación realizada por el Espíritu en nosotros es descrita por Pablo como "una nueva creación": "pero habéis sido lavados, habéis sido santificados, habéis sido justificados en el nombre del señor Jesucristo y en el Espíritu de nuestro Dios" (ICor. 6, 11; cf. IICor. 5, 17; Gál. 3, 27, 6.15; Ef. 4, 24; Rm. 15, 16). 
2.2.- El Espíritu Santo nos configura con Jesucristo. El Espíritu Santo "nos identifica con Jesús-Camino, abriéndonos al misterio de salvación para que seamos hijos del Padre y hermanos unos de otros; nos identifica con Jesús-Verdad, enseñándonos a renunciar a nuestras mentiras y propias ambiciones, y nos identifica con Jesús-Vida, permitiéndonos abrazar su plan de amor y entregarnos para que todos tengan vida en Él" (CELAM: "Documento de Aparecida, Brasil, 2007, n. 137).

2.3.- El Espíritu Santo nos hace reconocer en Jesús de Nazaret al Señor: "Nadie puede decir: “¡Jesús es el Señor!” sino por influjo del Espíritu Santo" (ICor. 12,3). Este mismo Espíritu es el que hace que el hombre oiga y escuche la llamada de Jesús a seguirlo de cerca por los caminos del Reino: "el que no tiene el espíritu de Cristo, no es de Cristo" (Rm. 8, 9).

2.4.- El Espíritu Santo nos invita a portarnos como hijos de Dios: "No caminéis según la carne, sino según el espíritu... porque el sentir de la carne es muerte; mas el sentir del espíritu, vida y paz" (Rm. 8, 4.6). "Caminad en espíritu, y no pondréis por obra los deseos de la carne" (Gál. 6, 16). Él nos guía: "todos los que son guiados por el Espíritu de Dios son hijos de Dios" (Rm. 8, 14). Recordemos también esta advertencia que nos da San Pablo: "Si vivimos gracias al Espíritu, procedamos también según el Espíritu” (Gál. 5, 25).

2.5.- El Espíritu Santo, haciéndonos hijos en el Hijo, da testimonio de la paternidad de Dios, nos hace conscientes de nuestra filiación adoptiva y nos da el valor y la fuerza de llamar a Dios con la palabra entrañable "¡Abba! ¡Padre!": "Recibisteis un espíritu de hijos adoptivos que nos hace exclamar: ¡Abba, Padre". El Espíritu mismo se une a nuestro espíritu para dar testimonio de que somos hijos de Dios. Y, si hijos, también herederos; herederos de Dios y coherederos de Cristo..." (Rm. 8, 15-17). Y como es propio de los hijos comunicarse con sus Padres, el Espíritu nos ayuda a orar: "El Espíritu viene en ayuda de nuestra flaqueza. Pues nosotros no sabemos pedir como conviene; más el Espíritu mismo intercede por nosotros con gemidos inefables” (Rm. 8, 26) y clama en nuestra alma: “AAbba, Padre!” (Gál. 4, 6). No puede haber auténtica oración sin la presencia del Espíritu Santo en nosotros.

2.6.- El Espíritu nos concede sus dones y frutos: “Que el Reino de Dios no es comida ni bebida, sino justicia y paz y gozo en el Espíritu Santo" (Rm. 14, 17). Recordemos los frutos del Espíritu Santo: "amor, alegría, paz, tolerancia, agrado, generosidad, lealtad, sencillez, dominio de sí” (Gál. 5,22-23).

2.7.- El Espíritu Santo obra en nosotros la fe en Jesucristo: “Os hago saber que nadie, hablando por influjo del Espíritu de Dios, puede decir: “¡Anatema es Jesús!”; y nadie puede decir: “¡Jesús es Señor!” sino por influjo del Espíritu Santo" (ICor. 12, 3; cf. Gál. 5, 5). Asimismo, infunde el amor 
y engendra la comunión en nosotros: "el amor de Dios ha sido derramado en nuestros corazones por el Espíritu Santo que se nos ha dado" (Rm.5,5), y la libertad ya que "donde está el Espíritu del Señor, hay libertad" (ICor. $3,17)$.Y también es la fuente de nuestra esperanza: "El Dios de la esperanza os colme de todo gozo y paz en vuestra fe, hasta rebosar de esperanza por la fuerza del Espíritu Santo" (Rm. 15, 13).

2.8.- El Espíritu Santo nos mantiene en tensión hacia nuestro destino final: "También nosotros, que poseemos las primicias del Espíritu, nosotros mismos gemimos en nuestro interior anhelando el rescate de nuestro cuerpo" $(\mathrm{Rm} .8,23)$, y es la prenda generosa que Dios nos ha regalado como anticipación y garantía de nuestra herencia futura: "El que nos marcó con su sello y nos dio en arras el Espíritu en nuestros corazones" (IICor. 1, 22). Finalmente podemos mirar el futuro con serenidad y paz ya que "si el Espíritu de Aquel que resucitó a Cristo Jesús de entre los muertos habita en vosotros, Aquel que resucitó a Cristo Jesús de entre los muertos dará también la vida a vuestros cuerpos mortales por su Espíritu que habita en vosotros" (Rm. 8, 11).

\section{3.- ¡No apaguemos el Espíritu en nosotros!}

El hombre puede contar siempre con la presencia y la ayuda del Espíritu Santo; pero también puede cerrarse al Espíritu Santo y no creer en Él ni aceptarlo: podemos estar en el Espíritu y podemos rechazar al Espíritu y, en consecuencia, apagarlo en nosotros: "No extingáis el Espíritu" (1Tes. 5, 19).

Quien ha recibido el Espíritu ha de esforzarse en llevar una vida consecuente con el Espíritu: Rm. 8, 4s.13; Gál. 5, 25.

\section{D}

\section{DIMENSIÓN ECLESIOLÓGICA}

Otra de las dimensiones de la espiritualidad cristiana es sin duda alguna la eclesiológica ya que provoca una experiencia de comunión y encuentro con los demás discípulos del Señor. En efecto, la espiritualidad ha de cimentarse en la comunión viva con Dios Padre, Hijo y Espíritu, y ha de concretarse en el seguimiento de Jesús como único Salvador y Redentor y 
en la experiencia del Pueblo de Dios, anticipo del reino de Dios (cf. Jn. 17, 21; LG7).

Tengamos presente que la Iglesia está esencialmente arraigada en el misterio trinitario de Dios, de donde procede. San Cipriano de Cartago consideró a la Iglesia como "una muchedumbre unida en virtud de la unidad del Padre, del Hijo y del Espíritu Santo" (LG 4).

Desentrañemos esta dimensión eclesiológica de la espiritualidad.

1.- Jesucristo ha fundado la Iglesia,"sacramento universal de salvación" (AG 1).

Un cristiano, por tanto, no debe prescindir de la Iglesia ni rechazarla ya que se precipitaría en la soledad y estaría en contradicción con su mismo ser cristiano que incluye su pertenencia a la Iglesia (cf. LG 8-9).

El cristiano es aquel que percibe la revelación de Dios, la acoge, responde a ella y la vive en la Comunidad eclesial que viene del Señor, de los Apóstoles y que es la Iglesia. Nuestros Obispos enseñan que "nuestra fe, por muy personal que sea, para ser verdaderamente teologal y salvadora, ha de ser participación viva de la fe de la Iglesia" (TDV 32).

2.- Aspectos de la espiritualidad implicados en la Iglesia

"Hoy se busca una espiritualidad, tanto en amplitud como en profundidad, en el marco de la vida misma de la Iglesia más que en las elaboraciones sistemáticas..., donde se descubre al presencia y el soplo vivificante del Espíritu" (J. Castellano: "Linee emergente della spiritualità oggi", RivVitSp 43 (1889), 8). K. Rahner decía que uno de las características de la espiritualidad era: "una espiritualidad fundada en la nueva eclesialidad" ("Espiritualidad antigua y actual", en "Escritos de Teología, VII. Taurus. Madrid 1969, 13-35).

Exponemos a continuación algunos rasgos esenciales de la Iglesia y desde ellos descubriremos aspectos diversos de la espiritualidad cristiana.

2.1.- Una comunidad de elegidos y llamados por Dios

Dios nos llama y nos reúne por medio de Jesucristo que ha salido a los caminos del mundo para llamar, convocar, reunir a todos, empezando por los pobres, los desvalidos, los excluidos y marginados... Más aún, Jesús envía mensajeros diciéndoles: "Salid a los caminos e invitad a todos los que encontréis al banquete...". San Pablo lo expresa de forma admirable en su carta a os Efesios al afirmar: "Bendito sea el Dios y Padre de nuestro Señor Jesucristo (...) por cuanto nos ha elegido en él antes de la creación del mundo para ser santos e inmaculados en sui presencia, en el amor..." (Ef. 1, 3-4). 
La espiritualidad cristiana hunde sus raíces en la elección y llamada que Dios en Cristo por el Espíritu Santo nos ha dirigido a la fe. Cristiano es aquel que refiere su persona y su vida entera a Dios que "da sentido a toda la vida, pero si se le elimina de la historia todo pasa a se provisional" (CEE: "La Verdad os hará libres", 28). En efecto, "sólo Dios da respuesta cabal a las aspiraciones profundas del hombre" (ib. 35).Por ello, podemos decir que el hombre está suscitado y sostenido, alumbrado y llamado por Dios al Misterio Trinitario. San Agustín formuló esta doctrina de forma sapiencial

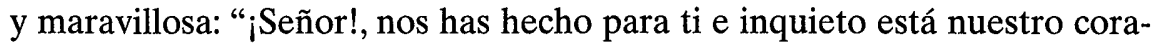
zón hasta que descanse en ti" (San Agustín).

\section{2.- Una comunidad de hijos de Dios}

En esta comunidad fraterna los cristianos aprendemos a invocar a Dios con la palabra entrañable "¡Padre!” y a poner nuestra entera confianza en Él que es entrañable y compasivo, misericordioso y bondadoso, salvador y liberador. El Apóstol manifiesta: "Dios ha enviado a nuestros corazones el Espíritu de su Hijo que clama ¡Abba, Padre! De modo que ya no eres esclavo sino hijo" (Gál .4, 6-7).

La espiritualidad cristiana ha de ser una espiritualidad filial por lo que ha de potenciar la oración, la confianza, la escucha de la Palabra de Dios, la obediencia a Dios. En efecto, Jesús, a quien debemos seguir e imitar, vivió su filiación desde las claves de la oración, de la obediencia, de la entrega, la confianza.

2.3.- Una comunidad de hermanos

Esta comunidad es la gran familia de los hermanos de Jesús. Por eso, todos debemos cuidar la comunión fraterna, evitar aquellas actitudes y comportamientos que destruyen la comunión eclesial, promover la comunión en fidelidad a la oración de Jesús a su Padre, en sintonía con la oración de Jesús: "Que todos sean uno. Como tú, Padre, en mí y yo en ti, que ellos también sean uno en nosotros, para que el mundo crea que Tú me has enviado" (Jn. 17, 21). San Pablo expresó esto con las siguientes palabras: "Un solo Cuerpo y un solo Espíritu, como una es la esperanza a la que habéis sido llamados. Un solo Señor, una sola fe, un solo bautismo, un solo Dios y Padre de todos, que está sobre todos, por todos y en todos" (Ef. 4, 16). Después de haber expuesto estos principios de la unidad de la Iglesia, Pablo afirma: "Todos los bautizados en Cristo os habéis revestido de Cristo: ya no hay judío ni griego; ni esclavo ni libre; ni hombre ni mujer, ya que todos vosotros sois uno en Cristo Jesús" (Gál. 3, 27-28).

La espiritualidad cristiana ha de promover e intensificar el rasgo peculiar de la comunión que tiene su fundamento en la eclesiología de comunión, 
promovida por el Concilio Vaticano II (cf. Sínodo de los Obispos de 1985 II C, 1). Juan Pablo II explica esta espiritualidad comunional (cf. NMI 43), y dice de ella: "sin este camino espiritual, de poco servirían los instrumentos externos de la comunión. Se convertirían en medios sin alma, máscaras de comunión más que sus modos de expresión y crecimiento" (NMI 43).

Como compromiso ofrecemos estas palabras de un teólogo de nuestros días: "Tenemos como inmensa tarea histórica por delante suscitar una Iglesia realmente fraternal, donde la diversidad de carismas no anula la fraternidad previa, ni la última autoridad responsable hace innecesaria la previa responsabilidad de todos" (O. González de Cardedal: "La entraña del Cristianismo", Salamanca, 33). Y también las de un Obispo que nos pone en la buena dirección: "Cuando los cristianos vivimos abiertos a la gran Iglesia y convivimos realmente con nuestros hermanos dentro de ella, a pesar de las diferencias que se dan entre nosotros, unos a otros nos enriquecemos en un esfuerzo constante por conseguir y conservar la verdadera unidad" (TDV 38).

2.4.- En esta Comunidad fraterna, cada uno ha recibido un don

En la Iglesia el Espíritu Santo reparte sus dones o carismas a los bautizados para que lo pongan al servicio de los demás y para la edificación del Cuerpo de Cristo: "A cada cual se le otorga la manifestación del Espíritu para provecho común. Porque a uno se le da por el espíritu palabra de sabiduría, a otro palabra de ciencia según el mismo Espíritu; a otro fe, en el mismo Espíritu..." (ICor. 12,7-9).

A los que presiden en nombre y autoridad de Jesucristo la Iglesia les corresponde promover y favorecer una cultura de comunión caracterizada por la corresponsabilidad, la coparticipación, la colaboración...

La espiritualidad cristiana ha de incluir la participación en la vida y misión de la Iglesia desde el don, carisma o ministerio que cada uno haya recibido del Señor; y ha de participar siempre en unión y en coordinación fraterna con los demás. No nos mostremos pasivos e indiferentes ante la vida y misión de la Iglesia. Nadie debe permanecer ocioso. El Señor nos llama e invita a todos a trabajar en "su viña", sabiendo que quien da el incremento es Él.

2.5.- Una Comunidad que celebra la fe

En esta Comunidad fraterna, animada y vivificada por el Espíritu Santo, los cristianos estamos llamados a celebrar la fe en la oración, en la Eucaristía y en los sacramentos: "Porque yo recibí del Señor lo que os he transmitido: que el Señor Jesús, la noche en que fue entregado, tomó pan...y dijo: "Este es mi cuerpo que se da por vosotros; haced esto en recuerdo mío..." (ICor. 11, 23ss). El Apóstol dice a los participantes en la Eucaristía: 
"Examínese, pues, cada cual, y coma entonces del pan y beba del cáliz..." (ICor.11, 28)

El Concilio Vaticano II resalta con énfasis la excelencia e importancia de la Eucaristía en la Iglesia afirmando: "No se edifica ninguna comunidad cristiana si no tiene como raíz y quicio la celebración de la sagrada Eucaristía (...) Esta celebración, para que sea sincera y cabal, debe conducir lo mismo a las obras de caridad y de mutua ayuda de unos para otros que a la acción misional y a las varias formas del testimonio cristiano" (PO 6). Hermoso e interpelante texto que debe encontrar en todos y en cada uno una acogida sincera y una respuesta adecuada.

La espiritualidad cristiana contiene una referencia explícita a la celebración y participación en la Eucaristía y en los demás sacramentos. "La innovación litúrgica no puede restringirse a las ceremonias, ritos, textos, etc. y a la participación activa, tan felizmente aumentada después del Concilio; no consiste sólo en la actividad externa, sino, en primer lugar, en la participación interna y espiritual, en la participación viva y fructuosa del misterio pascual de Jesucristo" (Sínodo Extraordinario de los Obispos sobre el Concilio Vaticano II, B, 1).

2.6.- La Comunidad cristiana "abraza a todos los afligidos" (LG 8)

Esta Comunidad fraterna debe tener bien abiertos los ojos y los oídos para ver y escuchar el clamor de los pobres y excluidos, en los que está presente el grito de Dios, y responder a esos necesitados como el Buen Samaritano. San Pablo hace una fuerte denuncia de la praxis sacramental de algunos cristianos de Corinto. Escuchemos nuevamente las palabras de Pablo: "Cuando os reunís, pues, en común, eso ya no es comer la Cena del Señor, porque cada uno se adelanta a comer su propia cena, y mientras uno pasa hambre, otro se embriaga" (ICor. 11,20-21). El cristiano auténtico intenta por todos los medios a su alcance hacer realidad las palabras de san Pablo: "Si sufre un miembro, todos los demás sufren con él" (IICor. 12, 26).

La espiritualidad cristiana será una espiritualidad encarnada. En efecto, "la vocación de los fieles laicos a la santidad implica que la vida según el Espíritu se exprese particularmente en su inserción en las realidades temporales y en su participación en las actividades terrenas" (ChFL 17; cf. AA 4). Una espiritualidad de inserción en el mundo y de apertura a los valores humanos; una espiritualidad del compromiso al servicio de la vida, de la paz, de la justicia y en apertura al mundo nuevo (cf. GS 29). Una espiritualidad desencarnada, intimista, espiritualista no es conforme con la espiritualidad cristiana. 


\section{DIMENSIÓN EVANGELIZADORA}

La espiritualidad cristiana ha de expresar el carácter más dinámico del compromiso evangelizador de los cristianos. Teniendo en cuenta que la Iglesia "existe para evangelizar" (EN 14), hemos de afirmar con claridad que la espiritualidad de los cristianos no puede ser ajena a todo lo que se refiere a la difusión del evangelio: anuncio, testimonio, catequesis, amor al prójimo, hacer discípulos, transformar la sociedad. Estas formas evangelizadoras han de impregnar la espiritualidad cristiana.

1.- Los evangelizadores han sido llamados por el Señor por puro amor y gracia, no por sus méritos. Pablo tiene conciencia clara de que Jesucristo lo ha llamado por pura gracia y amor para anunciar el Evangelio:

"Pablo, siervo de Cristo Jesús, apóstol por vocación, escogido para el Evangelio de Dios" (Rm. 1,1). Lucas refiere en el los hechos de los Apóstoles que "el Señor contestó a Ananías: "Vete, pues éste me es un instrumento de elección que lleve mi nombre ante los gentiles, los reyes y los hijos de Israel" (Hech. 9, 15). El propio Pablo dice a los cristianos de Galacia: "os hago saber, hermanos, que el Evangelio anunciado por mí, no es cosa de hombres, pues yo no lo recibí ni aprendí de hombre alguno, sino por revelación de Jesucristo" (Gál. 11, 11-12). Y a los cristianos de Filipos les manifiesta: "Habiendo sido yo mismo alcanzado por Cristo Jesús" (Filp. 3, 12). Es siempre el Señor quien nos llama y nos envía al mundo a anunciar la Buena Noticia de Jesucristo hasta los confines de la tierra a todos los hombres y mujeres de la tierra pues "el hombre es el camino de la Iglesia" (RH 14).

2.- Los evangelizadores anuncian, como Pablo, a Jesucristo: "Nosotros predicamos a un Cristo crucificado" (ICor. 1,23). Esta es la Buena Noticia que la Iglesia ha de confiar y entregar a todos los hombres, hasta el punto que si nos e anuncia a Jesucristo no habrá evangelización en sentido propio y estricto, según enseñó Pablo VI. Cristo, el Hijo de Dios hecho hombre, es el Salvador y el Redentor de la humanidad porque "no hay bajo el cielo otro nombre dado a los hombres por el que nosotros debamos salvarnos" (Hech.4,12), afirma San Pedro en Jerusalén. Esta es la Buena Noticia que la Iglesia ha recibido y que ella predica hoy y entrega a las generaciones futuras. 
3.- Los evangelizadores anuncian a Jesucristo, y lo hacen porque han sido llamados, elegidos por el Señor para realizar esta tarea tan excelente. Traigamos a estas líneas el inicio de la misión de Bernabé y de Saulo: "Mientras estaban ayunando, dijo el Espíritu Santo: "Separadme ya a Bernabé y a Saulo para la obra a la que los he llamado... Ellos, pues, enviados por el Espíritu Santo, bajaron a Seleucia y de allí navegaron a Chipre" (Hech. 13,2-4). Recuperemos hoy la conciencia de ser elegidos, llamados por el Señor para llevar, como Pablo, su Santo Nombre a todos los hombres y mujeres de la tierra. Bueno es que recordemos las palabras de Jeremías: "Tú me sedujiste, Señor, y yo me dejé seducir".

4.- Los evangelizadores anuncian el Evangelio no en nombre propio, sino en nombre de Jesucristo nuestro Señor. Esta convicción y certeza dan paz y serenidad al espíritu de todo evangelizador, catequista, misionero...

Tener conciencia de esta realidad nos ha de llevar a agradecer al Padre por Cristo en el Espíritu el don inmenso e inmerecido de participar en la tarea evangelizadora iniciada y no acabada aún: podríamos decir que estamos en los comienzos de la evangelización. Una persona espiritual es aquella que reconoce este don de Dios, lo acoge y da gracias. ¡Qué palabras tan sencillas, y con qué facilidad se olvidan hoy!

5.- Los cristianos debemos estar plenamente convencidos de que el Evangelio que anunciamos es el gran Don y la mejor Noticia que el hombre y la mujer de hoy necesitan escuchar y recibir hoy y siempre. Tenemos la certeza de que los criterios y valores evangélicos hacen posible la defensa de la dignidad y de los derechos humanos de toda persona, abriéndola siempre a un horizonte de esperanza y de trascendencia. Por otra parte, los cristianos estamos convencidos de que el mensaje evangélico contribuye a la construcción de una nueva sociedad fundamentada en los valores de la paz y de la justicia, de la fraternidad y de la solidaridad entre todos los hombres.

Con palabras vigorosas Pablo dice a los cristianos de Corinto: "Así, mientras los judíos piden señales y los griegos buscan sabiduría, nosotros predicamos a un Cristo crucificado: escándalo para los judíos, necedad para los gentiles; mas para los llamados, lo mismo judíos que griegos, un Cristo, fuerza de Dios y sabiduría de Dios" (ICor. 1,22-24). Con esta firmeza y convicción habla Pablo a los cristianos de Corinto. ¡Qué gran testimonio! ¡Qué interpelación tan exigente para todos nosotros, cristianos del siglo XXI!

6.- Los evangelizadores, en presencia de las dificultades como pueden ser: el poco éxito de su acción pastoral, la respuesta insuficiente de aquellos 
a quienes llaman, la indiferencia religiosa, el laicismo imperante... no han de caer en el pesimismo, ni en la desesperanza, antes bien han de descubrir los posibles o reales fallos para pedir perdón a Dios de ellos y para corregirlos con la ayuda de la gracia divina. El desaliento, la desesperanza, el cansancio...no son buenas actitudes para el evangelizador, el misionero, el catequista, el pastor...

Contemplemos una vez más a Pablo, de quien Lucas refiere que fue perseguido en la ciudad de Corinto, y que ante esta situación dolorosa le dijo el Señor: "No tengas miedo, sigue hablando y no calles; porque yo estoy contigo y nadie te pondrá la mano encima para hacerte mal, pues tengo yo un pueblo numeroso en esta ciudad" (Hech. 18, 9).

¡No tengáis miedo! Nos dice el Señor hoy y aquí a todos nosotros. ¡Levántate y come; ponte en camino, que aún te queda mucho trecho que recorrer...!, nos dice el Señor hoy a nosotros como en otro tiempo al profeta Elías en los bordes del desierto camino hacia el Horeb. ¡Ponte en camino, que yo estoy a tu lado; y "cuando hay que subir monte (Calvario lo llama Él), siento en su mano amiga, que me ayuda, una llaga dolorosa". ¿Esta es nuestra experiencia cristológica y apostólica?

7.- Los evangelizadores han de anunciar a Jesucristo sabiendo que Jesucristo está con ellos hasta el fin del mundo (Mt. 28,20) y que el Espíritu Santo los acompaña siempre (Jn. 20,22) para fortalecerlos en medio de las dificultades y persecuciones y para que no les falten las palabras que han de pronunciar y proclamar. No vamos solos por la vida

Recordemos la experiencia de Pablo que afirma: "todo lo puedo en Aquel que me conforta" (Filp. 4, 13). La fuerza del Espíritu Santo que sostuvo a Pablo es la que hoy sostiene a la Iglesia y a los evangelizadores. Pablo dice a los presbíteros de Éfeso: "Ahora os encomiendo a Dios y a la palabra de su gracia, que tiene poder para construir el edificio y daros la herencia con todos los santificados" (Hech. 20,32).

El evangelizador no debe desfallecer nunca en el empeño evangelizador aunque el camino esté lleno de obstáculos, pues el Señor nunca lo abandona y la paciencia cristiana es siempre activa y dinámica, nunca conformista y pasiva.

8.- Los evangelizadores han de estar preparados y formados para dar razón de su fe y de su esperanza a quienes se la pidan. No basta con recitar unas fórmulas teóricas hechas y que se repiten; es necesario también dialogar con los que no creen, con los agnósticos, con los que han perdido la fe. Es necesario hacer un gran esfuerzo para personalizar la fe, superando la fe 
heredada. Esto se hace posible y real a través de verdaderos y auténticos testigos de Jesucristo en la Iglesia y en el mundo.

Para hacer realidad estos buenos deseos es necesario cuidar la formación permanente de los agentes de pastoral. Recordemos la exhortación que Pablo hace a los presbíteros de Éfeso en su emotiva y entrañable despedida de ellos, y en ellos a nosotros: "tened cuidado de vosotros y de toda la grey, en medio de la cual os ha puesto el Espíritu Santo como vigilantes para pastorear la Iglesia de Dios, que él se adquirió con su propia sangre" (Hech. 20,28).

9.- Hemos de anunciar el Evangelio como Buena Noticia de Salvación a todos, especialmente a los pobres y desvalidos, a los que sufren y a los nada tienen o nada son, a los excluidos e irrelevantes.

Pablo sale en defensa de los pobres y necesitados; no se desentiende de ellos. A unos cristianos de Corinto Pablo les dice que deben compartir con los necesitados hasta el punto que si no lo hacen su participación en la Eucaristía no es correcta: "Cuando os reunís en común, eso ya no es comer la Cena del señor, porque cada uno se adelanta a comer su propia cena, y mientras uno pasa hambre, otro se embriaga" (ICor. 11, 20-21).

Estas palabras de Pablo han de ser para la Iglesia, para las Comunidades cristianas y para cada uno de nosotros una interpelación fuerte y urgente ya que la credibilidad de la Iglesia pasa por su dedicación a atender a los pobres y necesitados, a los marginados y excluidos, a los desvalidos e irrelevantes. ¿Qué hemos hecho de Cristo cuando tantos pobres mueren de hambre?

10.- Han de estar preparados para asumir y entender las respuestas que los hombres den al anuncio del Evangelio que ellos hacen, sin caer en el optimismo ingenuo ni en la desesperanza paralizante.

Unos acogen el evangelio con gozo y alegría;

Otros se muestran indiferentes ante tal anuncio;

Otros lo consideran necedad y escándalo;

Otros llegan a despreciarlo.

Aunque haya muchas personas que rechacen el Evangelio de Jesucristo, los que hemos tenido la inmensa dicha de creer en Dios, los que hemos recibido el don de la fe y respondido a él, debemos seguir proclamando y anunciando, a tiempo y a destiempo, el evangelio, acompañándolo con el testimonio personal. 
11.- Evangelicemos aunque seamos perseguidos, injuriados, calumniados, encarcelados... En más de una ocasión el evangelizador, el misionero... Los evangelizadores han de estar dispuestos a sufrir y dar su vida por Jesucristo y su Evangelio, si llegara el caso. En esos momentos, han de poner toda su confianza en el Señor, han de fiarse del Señor aun en medio de la zozobra y de la angustia. De este modo podrán experimentar la presencia del Señor a su lado dándoles fuerza y sosteniéndolos en el dolor y el sufrimiento por el Evangelio. La entrega incondicional y el testimonio valiente de tantos santos y mártires son la mejor confirmación de lo que acabamos de afirmar.

Valladolid, 10 de octubre de 2008

Mons. Francisco Cerro Chaves † Obispo de la Diócesis de Coria-Cáceres 